\title{
Cervical Muscle Activity During Loaded Arm Lifts in Patients 10 Years Postsurgery for Cervical Disc Disease
}

\author{
Anneli Peolsson, Michael N. Peolsson, Gwendolen A. Jull and Shaun P. OLeary
}

\section{Linköping University Post Print}

\section{Tweet}

N.B.: When citing this work, cite the original article.

Original Publication:

Anneli Peolsson, Michael N. Peolsson, Gwendolen A. Jull and Shaun P. OLeary, Cervical Muscle Activity During Loaded Arm Lifts in Patients 10 Years Postsurgery for Cervical Disc Disease, 2013, Journal of Manipulative and Physiological Therapeutics, (36), 5, 292-299. http://dx.doi.org/10.1016/j.jmpt.2013.05.014

Copyright: Elsevier http://www.elsevier.com/

Postprint available at: Linköping University Electronic Press http://urn.kb.se/resolve?urn=urn:nbn:se:liu:diva-96997 


\title{
Cervical Muscle Activity DuRINg LoAded ARM Lifts In Patients
}

\section{YeARS POST-SURgery For CERVICAL DISC DISEASE}

\author{
Anneli LC. Peolsson, PT, PhD, ${ }^{\mathrm{a}, \mathrm{b}}$ Michael N. Peolsson MSc CE, PhD, ${ }^{\mathrm{c}}$ Gwendolen A. Jull, \\ PhD, PT ${ }^{\mathrm{b}}$ Shaun P. O’Leary PT, PhD ${ }^{\mathrm{b}, \mathrm{d}}$
}

${ }^{a}$ Department of Medical and Health Sciences, Division of Physiotherapy, Faculty of Health Sciences, Linköping University, Linköping, Sweden; ${ }^{\mathrm{b}}$ NHMRC CCRE (Spinal Pain, Injury and Health), The University of Queensland, Brisbane, Australia; ${ }^{\mathrm{C}}$ Computational Life Science Cluster and Department of Chemistry, Umeå University, Umeå, Sweden and ${ }^{\mathrm{d}}$ Physiotherapy Department, Royal Brisbane and Womens Hospital, Queensland Health, Queensland, Australia.

Corresponding author: Assoc. Prof. Anneli Peolsson, NHMRC CCRE (Spinal Pain, Injury and Health), The University of Queensland, St Lucia, QLD 4072, Brisbane, Australia, Email: a.peolsson@uq.edu.au; Anneli.Peolsson@liu.se, Facsimile: +61-7-33652775, Telephone: +61-7-33652209

KEY INDEXING TERMS: Neck Muscles, Neck Pain, Surgical Procedure, Motor Skills,

Ultrasonography

\section{CONFLICTS OF INTERESTS}

The authors declare no conflicts of interests.

\section{ACKNOWLEDGEMENTS}

Anneli Peolsson is supported by the Swedish Medical Research Council, the Wenner-Gren foundations and the Ann-Mari and Ragnar Hemborg foundations for Manual Therapy. Shaun O’Leary is supported by a Health Practitioner Research Fellowship (Queensland Health and University of Queensland (NHMRC CCRE Spinal Pain, Injury and Health)). 


\section{Practice of applications}

- Evaluating potential impairments in individuals with persistent disorders following cervical surgery will permit a more structured approach to rehabilitative exercise for this understudied group.

- Greater muscle mechanical activity levels were observed in the ventral muscles and dorsal multifidus muscle of patients with persistent symptoms following anterior cervical decompression and fusion.

- The differences may indicate an altered motor strategy in this group when performing the upper limb task.

- The altered motor strategy need to be considered when prescribing exercise for their rehabilitation. 


\section{ABSTRACT}

Objective: To compare the mechanical activity of the neck muscles during loaded arm lifting tasks in individuals with longstanding disability after anterior cervical decompression and fusion (ACDF) to that of healthy controls.

Methods: Ten individuals (mean age 60 years; SD 7.1) who underwent ACDF (10-13 years previously) for cervical disc disease and 10 healthy age- and gender-matched controls participated in the study. Ultrasonography were used to investigate the degree of deformation and deformation rate of ventral and dorsal neck muscles at the C4-segmental level during a single $\left(1 \mathrm{x}\right.$ arm flexion to $\left.120^{\circ}\right)$ and repeated $\left(10 \mathrm{x}\right.$ arm flexion to $\left.90^{\circ}\right)$ loaded arm elevation condition.

Results: The ACDF group demonstrated greater deformation and deformation rate of the longus capitis $(\mathrm{p}=0.02)$ as well as deformation rate of the sternocleidomastoid $(\mathrm{p}=0.04)$ during the $120^{\circ}$ arm lift. For repeated $90^{\circ}$ arm lift, there was a significant effect of group with higher deformation rate values observed in the longus capitis ( $\mathrm{p}=0.005-0.01)$ and multifidus $(p=0.03)$ muscles in the ACDF group. Muscle behavior did not change the repeated arm lifts (no group x time interactions) for either the ventral or dorsal muscles.

Conclusions: Greater muscle mechanical activity levels were observed in the ventral muscles as well as the multifidus muscle, of patients with persistent symptoms following ACDF. These differences may be indicative of an altered motor strategy in this patient group when performing the upper limb task and may need to be considered when prescribing exercise for their rehabilitation.

Key Indexing Terms: Neck Muscles, Neck Pain, Surgical Procedure, Motor Skills, Ultrasonography 


\section{INTRODUCTION}

Individuals who have previously undergone anterior cervical decompression and fusion (ACDF) surgery for cervical disc disease often experience persistent mechanical neck pain and disability. ${ }^{1-5} \mathrm{~A}$ known feature of persistent neck pain disorders is altered muscle activity within the dorsal and ventral neck muscle layers irrespective of origin (traumatic or non traumatic). ${ }^{6-10}$ This is considered detrimental to the health of the cervical vertebral column that relies heavily on muscles for its optimal physical support. ${ }^{11}$ As such altered muscle activity, ${ }^{12,13}$ and the proposed consequential changes in loading to the spine, may contribute to the persistence of neck pain and disability in some individuals. ${ }^{14}$ However, compared to other conditions, ${ }^{12,13}$ the activity of cervical muscles in individuals following ACDF has not been widely studied. $^{15}$

Based on available evidence, it is reasonable to expect that individuals following ACDF may exhibit altered muscle activity. In addition, these individuals may have further physical insult to cervical structures during the surgical procedure that may affect the capacity of muscles to support the cervical spine. Certainly studies have shown deficits in strength and endurance of neck muscle in cervical post-surgical patients. ${ }^{1,5,16}$ While these studies demonstrate a gross loss of capacity of the muscles to generate and sustain cervical muscle force following ACDF, they do not shed light on motor strategies by which this patient group physically supports their neck under load. This information would be valuable from an exercise prescription perspective as incorporating exercise to train the differential activity of neck muscles has proven beneficial in other neck pain conditions. ${ }^{17,18}$

The purpose of the study was to compare the differential activity of the dorsal and ventral neck muscles layers during loaded lifting tasks in individuals with longstanding disability 
after ACDF, to that of healthy controls. The findings of this study may inform clinical decision making when prescribing exercise for individuals with persistent neck symptoms following ACDF surgery.

\section{METHODS}

\section{$\underline{\text { Participants }}$}

Ten volunteers (7 women and 3 men (mean $( \pm$ SD) age 60 ( \pm 7.1$)$ years) with a history of persisting pain and disability 10 to 13 years following ACDF surgery for cervical disc disease participated in this cross-sectional study. They reported a mean pain intensity of $36 \mathrm{~mm}( \pm$ 24.9) (on a $100 \mathrm{~mm}$ visual analogue scale $(\mathrm{VAS}))^{19}$ and scored an average of $31 \%( \pm 8.9)$ on the Neck Disability Index (NDI). ${ }^{20}$ All participants followed a standardized pathway of care following surgery. Participants used a Philadelphia collar for 6 weeks and received routine physical therapy at the Spine Clinic including basic ergonomics, light shoulder movements, and exercises to improve active range of neck motion after removal of the collar. Following this period any intervention was on a pragmatic basis in primary care.

Ultrasound measurements recorded from the ACDF surgical group were compared to those recorded from 10 healthy controls matched for gender and age (mean age 60 ( \pm 6.5 ) years). Participants were excluded from the control group if they reported a history of neck or shoulder pain or injury, scored 10mm or greater on a VAS (mean VAS $0.08( \pm 0.29) \mathrm{mm}$ ) when asked to rate their general level of neck discomfort, ${ }^{21}$ reported previous trauma to the neck or head, significant pain in the thorax or lower back, or any neurological or inflammatory conditions. 
This study received approval from the Regional Medical Research Ethics Committee at the Faculty of Health Sciences at Linköping University in Sweden and was conducted in accordance with the declaration of Helsinki. All participants received verbal and written information about the study and signed a consent form.

\section{$\underline{\text { Ultrasound Measurements }}$}

Ultrasound measurements of the cervical muscles were recorded with a $14.0 \mathrm{MHz}$ linear transducer (38 mm footprint) and an Ultrasound Vivid 9 Dimension (GE Healthcare, Horten, Norway) Unit utilizing a high frame rate (78 frames/s) operated in B-mode with a 2D ultrasound imaging system. Ultrasound images of cervical muscle activity were recorded during experimental lifting conditions which were later analyzed as image sequences (“videos”) using post-process speckle tracking analysis. Recordings were made for both the dorsal (upper trapezius, splenius, semispinalis capitis and cervicis, cervical multifidus) (Fig 1A) and ventral (sternocleidomastoid, longus capitis, longus colli) (Fig 1B) neck muscles. All recordings were made at the $\mathrm{C} 4$ vertebral level identified by palpation of the $\mathrm{C} 4$ spinous process for the dorsal muscles and by the carotid artery bifurcation ${ }^{22}$ for the ventral muscles. The transducer was first positioned in a transverse orientation at the marked C4 level on the right side and underlying muscle layers and bony landmarks were identified. The transducer was then rotated 90 degrees to a longitudinal orientation to the dorsal muscles providing the optimal image plane required for the post-process speckle tracking analysis (based on the stable Farneback mathematical model). ${ }^{15,23}$ The Multivariate Analysis of Congruent images (MACI) research software ${ }^{15,23}$ was used for the analysis. 
Participants performed the lifting tasks while a researcher maintained the accurate position of the ultrasound head over the targeted neck muscles. A similar procedure was used for the ventral muscles using the landmark of the carotid artery bifurcation.

Post-Process Speckle Tracking Analysis:

Post-Process speckle tracking analysis utilizes speckles (dots) contained within a muscular region of interest (ROI) to tag and track movement of muscle (due to muscle contraction) during exercise. The speckles (one for each pixel within the ROI) are fixed to specific points of the imaged muscle tissue and are tracked to measure displacement (per unit time) of the designated muscle points during contraction. A speckle tracking algorithm (pattern scattering recognition) calculates the median displacement value of all speckles within the ROI at sequential frames of the exercise video. The median value, in preference to the mean value, is used because it is less affected by speckle displacement outliers, and lost speckles between video frames. A stable mathematical model and at least $80 \%$ agreement between frames are sufficient for the software to identify the patterns of speckles and follow the changes in muscle deformation frame by frame. The first frame of all video sequences is recorded at rest immediately before the commencement of the lift. Deformation measurements calculated from this first frame are utilized as the reference value from which all deformation measurements from the frames recorded during the lifting events are calculated. This process permits two mechanical measurements of muscle activity to be calculated during the experimental lifting tasks:

Muscle Deformation (\% strain): Muscle deformation (strain) is defined as the momentary change (frame by frame) in muscle tissue displacement during contraction (elongation/shortening during exercise) relative to a reference length (recorded immediately prior to the commencement of the lift). Muscle deformation during the lifting task is 
expressed as a percentage of the pre-lift muscle length (\% strain). A higher number of percentages mean higher longitudinal deformation of the muscle.

Muscle Deformation Rate (\% strain/sec): Muscle deformation rate is defined as the deformation per second (\% strain/sec) providing information concerning the speed of muscle contraction. A higher deformation rate means a higher speed of the deformation.

These measurements have been shown to have moderate to excellent test-retest reliability both for dorsal (two-way random absolute agreement single measure Intra Class Correlation Coefficient (ICC) $0.61-0.99)^{24}$ and ventral (ICC 0.80-0.99) ${ }^{25}$ neck muscles. The deformation measurement is a mechanical measure of muscle activity (change in longitudinal length of muscle during activity). The magnitude of muscle deformation has been shown to be positively related to muscle activity during electrical stimulation in that a higher degree of stimulation was associated with a higher degree of muscle deformation. ${ }^{26}$ Similarly a linear correlation has been observed between the degree of voluntary muscle contraction (\% of MVC) and the corresponding degree of muscle deformation. ${ }^{26}$

Experimental Procedure

Ultrasound video sequences were recorded during two experimental loaded arm lifting tasks of the right upper limb (Fig 2AB). Both experimental tasks were performed in a standing position with the participant's gaze immediately ahead, their elbow straight, and the forearm in a neutral pronation/supination posture. During both experimental tasks ultrasound video recordings of the cervical muscles were made immediately before the commencement of the lifting task (utilized to calculate the reference resting deformation and deformation rate values) and continued over the duration of the lifting task. Recordings for the single loaded 
arm lift (Experimental Task 1) were performed first followed by recordings for the repeated loaded arm lift (Experimental Task 2).

Experimental Task 1 (Single loaded arm lift to $120^{\circ}$ ) - This task was designed to mimic daily lifting activities often reported as aggravating to neck pain such as placing objects on a shelf. Participants were instructed to elevate their arm in the sagittal plane until their index finger touched a horizontal bar in front of them that corresponded to $120^{\circ}$ shoulder flexion, before lowering the arm to the starting position. This lift was performed while holding a standardized weight in the hand (1 kg for women, $2 \mathrm{~kg}$ for men). The participants first practiced the test with their left arm for familiarization purposes. A metronome set at 40 beats per minute ensured that a consistent pace was maintained during the task such that they lifted their arm on the first beat of the metronome and lowered the arm on the second beat. Once participants could perform the movement with the left arm at the correct speed, the experimental condition was performed with the right arm. For all participants, recordings were made over one repetition of the lift for the dorsal muscles first followed by recordings for the ventral muscles. All participants then performed Experimental Task 2.

Experimental Task 2 (Repeated loaded lift to $90^{\circ}$ ) - This task was designed to mimic daily repeated low load upper limb activities such as hanging laundry on a clothes line. Participants were instructed to elevate their arm in the sagittal plane until their index finger touched a horizontal bar in front of them that corresponded to $90^{\circ}$ shoulder flexion, before lowering the arm to the starting position. This lift was repeated 10 times while holding a standardized weight in the hand ( $0.5 \mathrm{~kg}$ for women, $1 \mathrm{~kg}$ for men). Participants first practiced the task with their left arm for familiarization purposes with the metronome (ie. elevating arm on first beat and lowering on second beat at a rate of 40 beats per minute) ensuring a smooth motion between lifting phases. Once participants could perform the task correctly with the left arm, 
the experimental condition (10 repetitions) was performed with the right arm. Ultrasound video was recorded continuously over the 10 repetitions.

The mean pain value before and after the 120 degree condition was $35.1 \mathrm{~mm}$ and $35.4 \mathrm{~mm}$ ( $p=0.91$ ), respectively. The mean pain value before and after the repeated 90 degree arm condition was $35.4 \mathrm{~mm}$ and $37.5 \mathrm{~mm}$ ( $\mathrm{p}=0.39)$, respectively.

\section{Data Management and Statistical Analysis}

Measurements of muscle deformation and deformation rate were calculated from ultrasound video sequences of the experimental lifting tasks and were all expressed as root mean square (RMS) values. The RMS values are based on the curve of the changes in deformation and deformation rate over the entire lifting sequence in the longitudinal ultrasound projection for each lifting condition. Analyses were performed using a statistical package (SPSS version 20: IBM). Statistical significance was accepted at the 0.05 alpha level.

Experimental Task 1 - Deformation and deformation rate measurements were calculated from recordings of the single lift and compared between groups using a multivariate general linear model analysis.

Experimental Task 2 - Deformation and deformation rate measurements were calculated for the first and final (average of the $9^{\text {th }}$ and $10^{\text {th }}$ repetitions) repetitions of the repeated lifting sequence to assess the impact of repetition on the measurements of muscle activity. A repeated measures general linear model was used to evaluate group (ACDF, control) x time (between the first and final repetitions) interactions as well as to evaluate main effects of 
group for all muscles evaluated. A Bonferroni correction was used for multiple comparisons of the deformation and deformation rate measurements.

\section{RESULTS}

Experimental Task 1 - Data for the single lift to $120^{\circ}$ degrees for both the ACDF and control groups are shown in Table 1.

Deformation: The ACDF group demonstrated significantly greater deformation of the longus capitis muscle $(p=0.02)$ compared to the controls during the single lift to 120 degrees, as well as a non-significant trend for greater activity in the other ventral muscles (longus colli (p $=0.08)$, sternocleidomastoid $(\mathrm{p}=0.09))$. The only dorsal muscle to demonstrated a tendency for group differences was the multifidus (higher deformation in the ACDF group ( $p=0.07)$ ), with all other dorsal muscles similar between groups ( $\mathrm{p}>0.52)$.

Deformation Rate: Deformation rate during the lift was generally greater in the ACDF group compared to the controls in the ventral muscles (sternocleidomastoid ( $p=0.04$ ), longus capitis $(p=0.02)$, and a tendency for longus colli $(p=0.07))$ and similar between groups for the dorsal muscles $(\mathrm{p}>0.54)$.

Experimental Task 2 - Data for the repeated lifting condition $\left(1^{\text {st }}\right.$ and $9 / 10^{\text {th }}$ repetitions) are shown in Table 2 for both participant groups.

Deformation - There were no significant group $\mathrm{x}$ time interactions for either the ventral $(\mathrm{p}>$ $0.11)$ or dorsal $(\mathrm{p}>0.25)$ neck muscles indicating the pattern of muscle use between the first 
and final repetitions of the lifting task did not differ significantly between groups for any of the muscle examined. Significant main effects for group (indicating greater deformation overall combining data from the first and final repetitions) were observed in the ACDF group compared to controls for the longus capitis muscle $(p=0.005)$ and non-significant trends for the longus colli $(\mathrm{p}=0.09)$ and splenius capitis $(\mathrm{p}=0.08)$ muscles.

Deformation Rate - No significant group $\mathrm{x}$ time interactions were observed for the deformation rate measure for either the ventral $(p>0.31)$ or dorsal $(p>0.24)$ neck muscles over the repeated lifting task. Significant main effects of group were observed with the ACDF participants demonstrating greater deformation rates overall during the task compared to controls for the longus capitis $(p=0.01)$, and multifidus $(p=0.03)$ muscles.

Adverse Events - There were no reported adverse events during this experiment.

\section{DISCUSSION}

This study evaluated the mechanical activity of the dorsal and ventral neck muscles in patients with longstanding pain and disability following an ACDF, by comparing their responses to a control population during a single and a repeated, lifting task. It is relevant to study cervical muscle function during lifting in light of their activity during upper limb tasks ${ }^{7}$ and reports that lifting activities aggravate neck pain. ${ }^{27} \mathrm{~A}$ general tendency of group differences (Tables 1-3) were mostly observed for the ventral neck muscles and the deepest layer of the dorsal neck muscles (multifidus). The ACDF group showed generally greater amplitudes of deformation (longitudinal mechanical activity along the muscle fibers) and deformation rates (speed of deformation) of the ventral and dorsal multifidus muscles 
compared to the control group. These findings suggest that participants with longstanding pain and disability following ACDF may have some altered motor strategies to physically support the cervical vertebral column during lifting. The lack of significant group $\mathrm{x}$ time interaction (Table 2 and 3) for the repeated lifting task, however, indicates that while there may be some differences in muscle activity, it was a consistent pattern of activity between groups over the repetitions.

The findings of this study are consistent with previous reports of altered cervical motor strategies in individuals with mechanical neck pain, ${ }^{6,8,10}$ including altered strategies in response to tasks involving the upper limbs. ${ }^{6}{ }^{7}$ However findings differ from these previous studies in that the activity of the deep ventral (longus capitis and longus colli) and dorsal (multifidus) muscles in this current study were shown to be heightened in the ACDF patient group compared to controls, as opposed to the reduced activity in these muscles in participants with neck pain found in the previous studies. ${ }^{6-8,10}$

There may be many reasons for these discrepancies. Different patient populations were studied, surgical in this study versus idiopathic and traumatic neck. ${ }^{6-8,} 10$ Potentially the ACDF patients may experience different alterations in motor strategy because of any impact of surgery on muscle function (particularly the deeper ventral muscles in an anterior approach) or the impact of the fusion itself. The apparent heightened activity may reflect greater demands on the deep muscle system to support the cervical column in the long term post-surgery when adjacent segments may be at risk of added strain and accelerated degeneration due to altered biomechanics after fusion. ${ }^{26}$ Discrepancies may also reflect the different measures and test conditions utilised between the current and past studies. Previous studies have used electromyography (recording electrical neurophysiological events) or magnetic resonance imaging (MRI) (functional muscle MRI studies recording post exercise muscle metabolic events) measures of muscle activity, as opposed to the ultrasound method 
used in this study that measures a mechanical event in muscle (deformation/deformation rate) as an indicator of muscle activity. While there is initial evidence of a relationship between the magnitude of electrical muscle stimulation and muscle deformation as well as a linear correlation between the degree of voluntary muscle contraction and the corresponding degree of muscle deformation, ${ }^{28}$ further validation of these US measures are required. Differences in the direction of altered muscle activity (increased or decreased activity relative to that shown by control groups) between this and previous studies, may be due to the interpretation of the ultrasound measures. Irrespective, the findings in this and previous studies all indicate that when compared to controls, different cervical motor strategies are evident in those with persistent neck symptoms that seems to mostly effect the deeper muscle layers that may have potential implications for altered loading of pain-sensitive cervical structures.

\section{Clinical Implications}

The trend for altered behaviour in the deeper muscle layers of patients with persistent neck symptoms and disability during the lifting tasks adds further support to the body of evidence indicating altered behaviour of the deep sleeve of muscles that envelope the cervical vertebral

column (anterior and posterior) with mechanical neck pain. ${ }^{6-8,} 10$ We postulate that the findings of this and previous studies demonstrating other elements of motor dysfunction (deficits in strength and endurance) in individuals who have previously undergone ACDF surgery supports recommendations for the inclusion of dedicated motor training in these patients. Specifically the findings of this study suggest that a rehabilitative exercise program for this patient group may need to address coordination of activity between the deep and superficial layers of the dorsal and ventral muscle groups with a low load motor relearning 
approach as is recommended for other chronic neck pain disorders. ${ }^{10,}{ }^{29}$ While higher load training of strength and endurance of the neck muscles is also beneficial to individuals with

neck pain disorders, ${ }^{30,31}$ these modes of training may not address the deficits in coordination between the different muscle layers. ${ }^{10,} 29$ Therefore training programs for individuals with persistent symptoms following ACDF may need to address the multiple requirements of the motor system (eg. coordination, strength, endurance), including therapeutic exercises designed to improve the coordinated activity of the multiple muscle layers of the neck ${ }^{32}$ to optimize physical support of the cervical column during functional tasks such as lifting.

\section{Limitations and Future Recommendations}

In relation to the lifting task, participants' were all provided with standard weights to lift and this may not have provided an equal challenge to the cervical muscles of all participants. Heavier loads may have produced greater muscle activity and future studies will need to evaluate muscle function in patients following ACDF under more challenging conditions. We chose the relatively low loads to mimic those commonly encountered in everyday life and to prevent potential aggravation of pain in the ACDF patients. A further limitation is the method of the ultrasound measurement used for speckle tracking analysis. Measurements of muscle deformation were performed over a specific ROI within the muscle and may not provide an overall activity level representation of all regions of the muscles. Another limitation of the speckle tracking techniques is that it is time consuming. Due to the low number of participants in the study the study should be looked upon as a pilot study. However, as the ultrasound techniques give opportunity to quantify changes in muscle structure and function non-invasively in different layers of the neck muscles, it has potential clinical application, not at least as a visual feedback and as a pedagogical tool to be used when training patients' muscle coordination.” 


\section{CONCLUSION}

Ultrasound measurements of muscle deformation and deformation rate of the dorsal and ventral cervical muscles during lifting tasks were compared in participants with long-term persistent symptoms and disability following ACDF and healthy controls. Heightened deformation and deformation rates were generally observed in the ventral muscles and the dorsal multifidus muscle of the ACDF group. This altered activity was not affected when the lifting task was performed over many repetitions. These findings may represent a change in motor strategy of the cervical motor system in response to lifting in patients following $\mathrm{ACDF}$, and may need to be considered when designing exercise programs for their rehabilitation. 


\section{REFERENCES}

1. Peolsson A, Vavruch L, Öberg B. Disability after anterior decompression and fusion for cervical disc disease. Adv Physiother 2002;4:111-24.

2. Ylinen J, Savolainen S, Airaksinen O, Kautiainen H, Salo P, Häkkinen A. Decreased strength and mobility in patients after anterior cervical diskectomy compared with healthy subjects. Arch Phys Med Rehabil 2003;84:1043-7.

3. Peolsson A. Investigation of clinically important benefit of anterior cervical decompression and fusion. Eur Spine J 2007;16:507-14.

4. Hermansen A, Hedlund R, Vavruch L, Peolsson A. A comparison between the carbon fiber cage and the Cloward procedure in cervical spine surgery: A 10-13 year followup of a prospective randomized study. Spine 2011;36:919-25.

5. Peolsson A, Söderlund A, Lind B, Löfgren H, Engquist M, Vavruch L et al. Is physiotherapy alone as effective as a combination of anterior surgery and physiotherapy in patients with cervical disc disease? Functional outcome of a prospective randomized study. Spine 2012 Aug 8. [Epub ahead of print]

6. Falla D, Bilenkij G, Jull G. Patients with chronic neck pain demonstrate altered patterns of muscle activation during performance of a functional upper limb task. Spine 2004;29:1436-40.

7. Falla D, Jull G, Hodges P. Feedforward activity of the cervical flexor muscles during voluntary arm movements is delayed in chronic neck pain. Experimental Brain Research 2004;157:43-8.

8. Jull G, Kristjansson E, DallÀlba P. Impairment in the cervical flexors: a comparison of whiplash and insidious onset neck pain patients. Man Ther 2004;9:89-94. 
9. Cagnie B, O'Leary S, Elliott J, Peeters I, Parlevliet T, Danneels L. Pain-induced changes in the activity of the cervical extensor muscles evaluated by muscle functional magnetic resonance imaging. Clin J Pain 2011;27:392-7.

10. O'Leary S, Cagnie B, Reeve A, Jull G, Elliott JM. Is there altered activity of the extensor muscles in chronic mechanical neck pain? A functional magnetic resonance imaging study. Arch Phys Med Rehabil 2011;92:929-34.

11. Panjabi MM, Cholewicki J, Nibu K, Grauer J, Babat LB, Dvoral J. Critical load of the human cervical spine: an in vitro experimental study. Clin Biomech 1998;13:11-7.

12. Sheard B, Elliott J, Cagnie B, O'Leary S. Evaluating serratus anterior muscle function in neck pain using muscle functional magnetic resonance imaging. J Manipulative Physiol Ther. 2012;35:629-35.

13. Zakharova-Luneva E, Jull G, Johnston V, O'Leary S. Altered trapezius muscle behavior in individuals with neck pain and clinical signs of scapular dysfunction. $\mathrm{J}$ Manipulative Physiol Ther. 2012;35:346-53.

14. O’Leary S, Jull G, Kim M, Vicenzino B. Cranio-cervical flexor muscle impairment at maximal, moderate, and low loads is a feature of neck pain. Man Ther 2007;12:34-9.

15. Peolsson A, Löfstedt T, Trygg J, Peolsson M. Ultrasound imaging with speckle tracking of cervical muscle deformation and deformation rate: isometric contraction of patients after anterior cervical decompression and fusion for cervical disc disease and controls. Man Ther 2012;17:519-25.

16. Peolsson A, Kjellman G. Neck muscle endurance in non-specific neck-pain patients and in patients after anterior cervical decompression and fusion. J Manip Physiol Ther 2007;30:343-50. 
17. Falla D, O'Leary S, Farina D, Jull G. The change in deep cervical flexor activity after training is associated with the degree of pain reduction in patients with chronic neck pain. Clin J Pain 2012;28:628-34.

18. O'Leary S, Jull G, Kim M, Uthaikhup S, Vicenzino B. Training mode-dependent changes in motor performance in neck pain. Arch Phys Med Rehabil 2012;93:1225-33.

19. Scott J, Huskisson EC. Graphic representation of pain. Pain 1976;2:175-84.

20. Vernon H, Mior S. The neck disability index: a study of reliability and validity. J Manip Physiol Ther 1991;14:409-15.

21. Croft PR, Macfarlane GJ, Papageorgiou AC, Thomas E, Silman AJ. Outcome of low back pain in general practice: a prospective study. BMJ 1998;316:1356-9.

22. Roberts LK, Gerald B. Absence of both common carotid arteries. Am J Roentgenol 1978;130:981-2.

23. Peolsson M, Löfstedt T, Vogt S, Stenlund H, Arndt A, Trygg J. Modelling human musculoskeletal functional movements using ultrasound imaging. BMC Med Imaging 2010;10:9.

24. Peolsson A, Brodin L-Å, Peolsson M. A tissue deformation rate ultrasound imaging investigation of the dorsal neck muscles during resisted isometric extension. Man Ther 2010;15:567-73.

25. Peolsson M, Brodin L-Å, Peolsson A. Tissue motion pattern of ventral neck muscles: investigated by tissue velocity ultrasonography imaging. Eur J Appl Physiol 2010; 109:899-908. 
26. Matsunaga S, Kabayama S, Yamamoto T, Yone K, Sakou T, Nakanishi K. Strain on intervertebral discs after anterior cervical decompression and fusion. Spine 1999;24: $670-5$.

27. Ariëns GA, van Mechelen W, Bongers PM, Bouter LM, van der Wal G. Physical risk factors for neck pain. Scand J Work Environ Health 2000;26:7-19.

28. Lopata RG, van Dijk JP, Pillen S, Nillesen MM, Maas H, Thijssen JM, et al. Dynamic imaging of skeletal muscle contraction in three orthogonal directions. J Appl Physiol. 2010;109:906-15.

29. Jull GA, Falla D, Vicenzino B, Hodges PW. The effect of therapeutic exercise on activation of the deep cervical flexor muscles in people with chronic neck pain. Man Ther 2009;14:696-701.

30. Kay T, Gross A, Goldsmith C, Santaguida P, Hoving J, Bronfort G et al. Exercises for mechanical neck disorders. The Cochrane database of systematic reviews 2005 (Issue 3); Art NoCD004425

31. Salo PK, Häkkinen AH, Kautiainen H, Ylinen JJ. Effect of neck strength training on health-related quality of life in females with chronic neck pain: a randomized controlled 1-year follow-up study. Health Qual Life Outcomes. 2010;14:7525-8.

32. Jull GA, O'Leary SP, Falla DL. Clinical assessment of the deep cervical flexor muscles: the craniocervical flexion test. J Manipulative Physiol Ther. 2008;31:525-33. 


\section{Figure Legends}

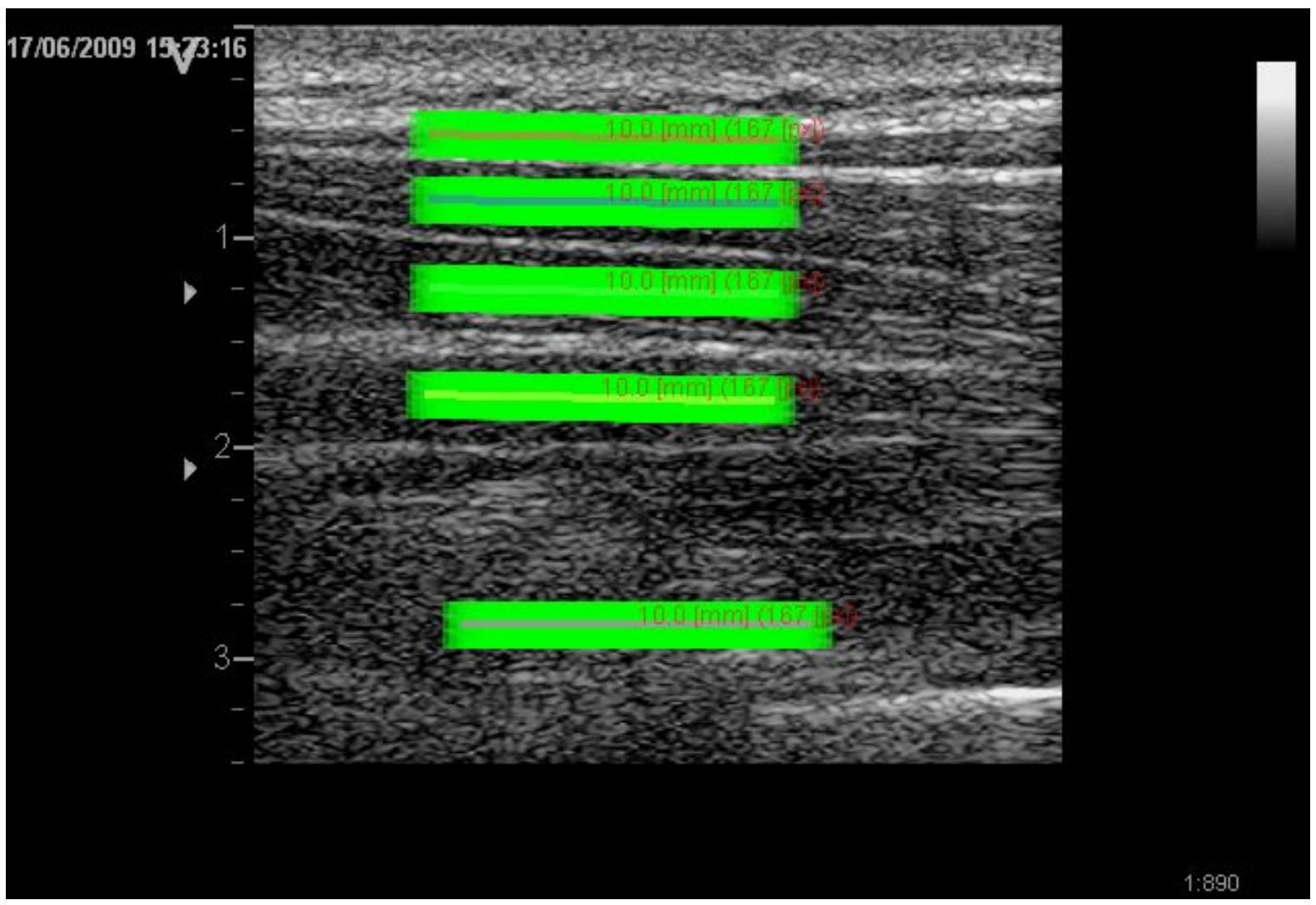

Fig 1A. Longitudinal ultrasound image of dorsal neck muscles with regions of interest (ROIs) from superficial to the deep: trapezius, splenius, semispinalis capitis, semispinalis cervicis and multifidus. 


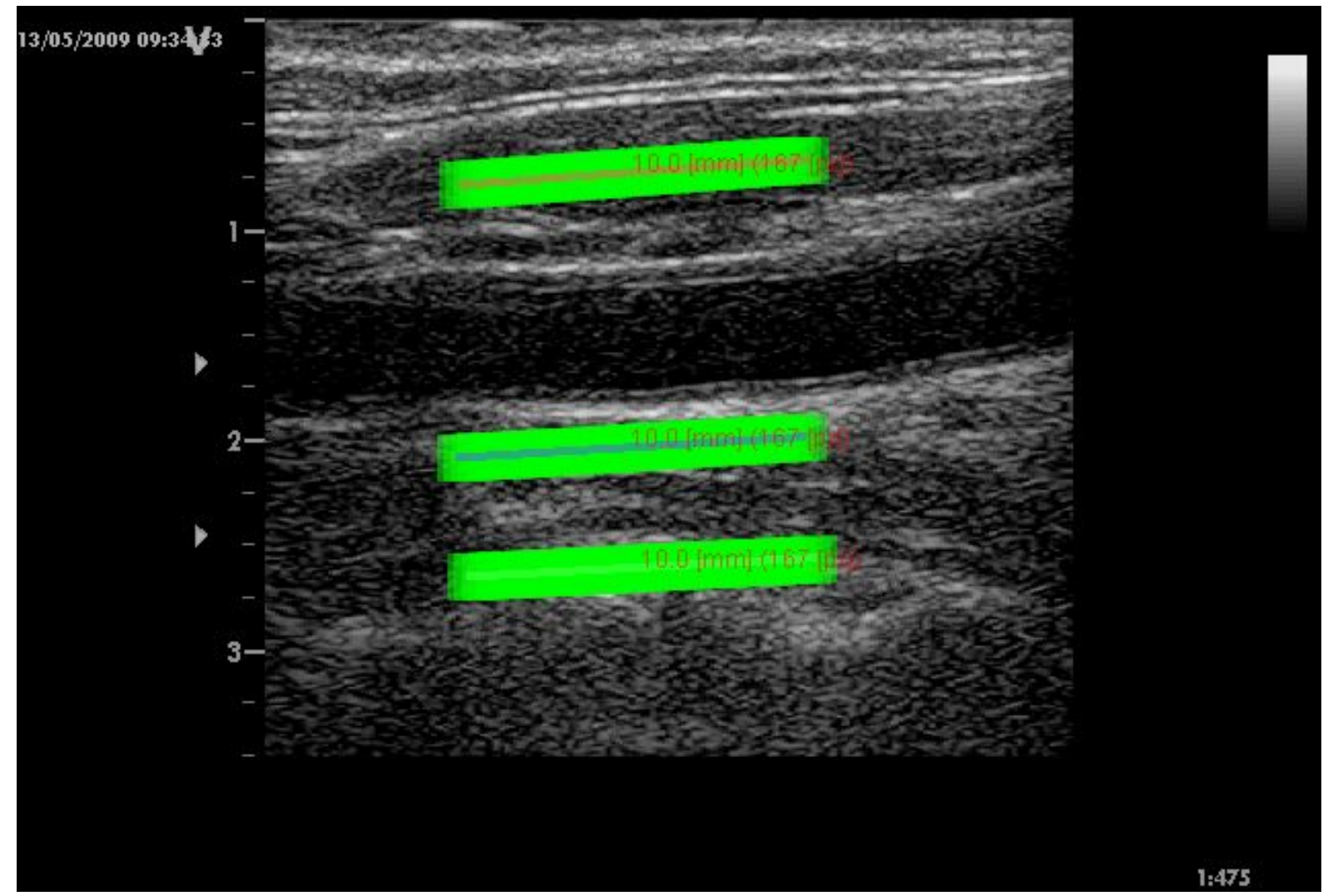

Fig 1B. Longitudinal ultrasound image of ventral neck muscles with regions of interest

(ROIs) from superficial to the deep: sternocleidomastoid, longus capitis and longus colli. 


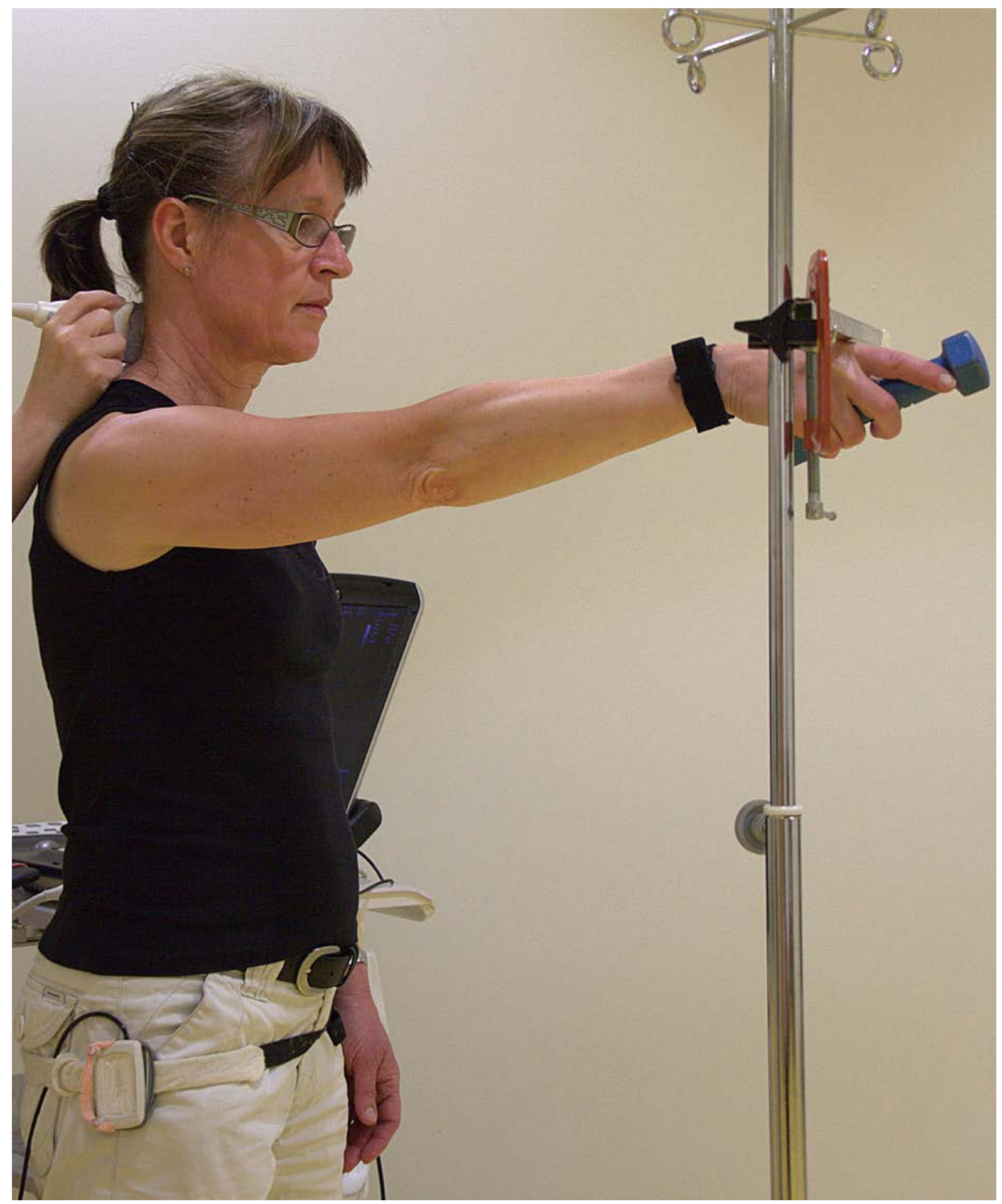

Fig $2 \mathrm{~A}$. Illustration of the $90^{\circ}$ repeated arm lift experimental procedure. 


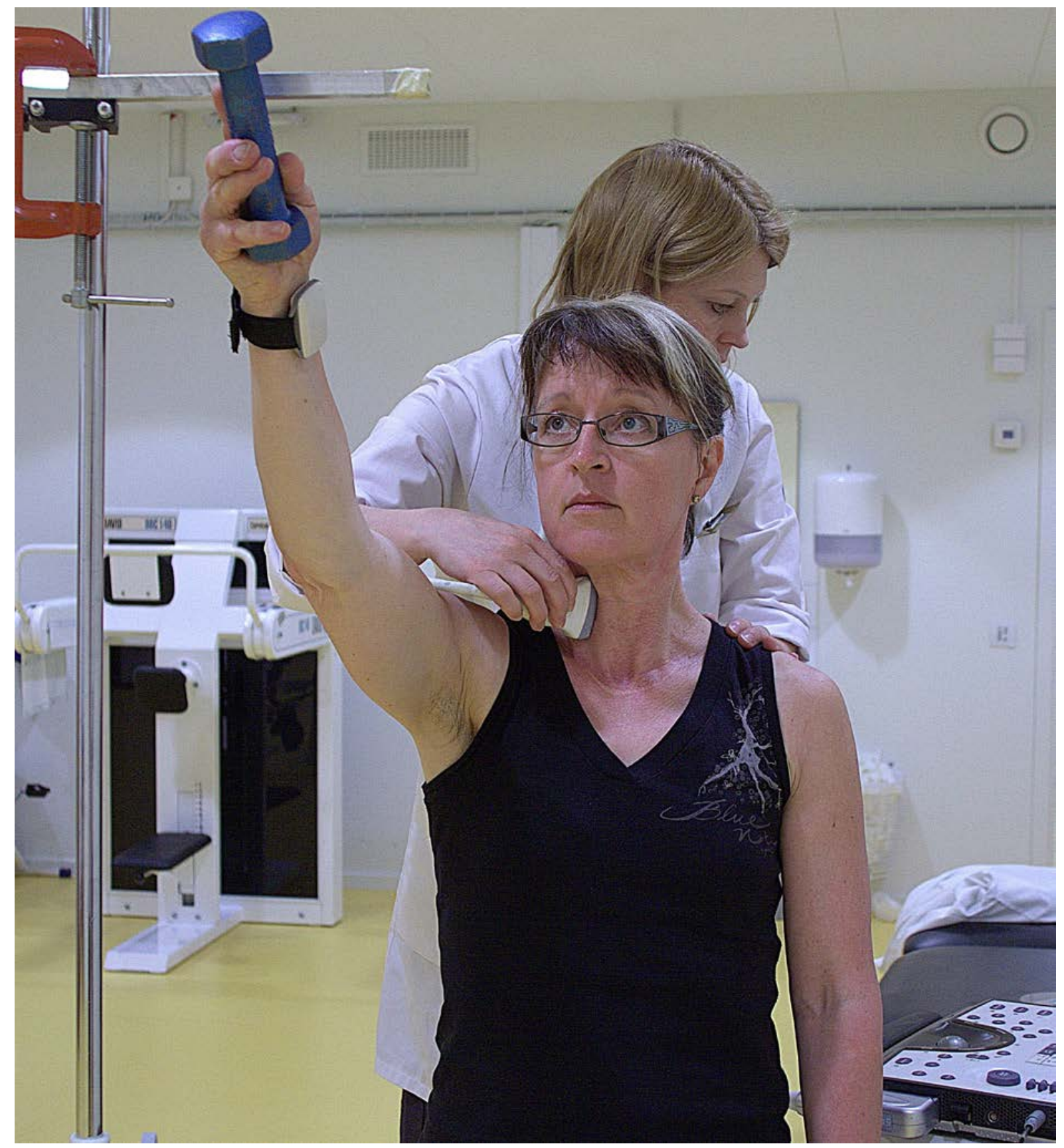

Fig 2B. Illustration of the $120^{\circ}$ single arm lift experimental procedure. 
Table 1) Descriptive statistics (mean (standard deviation) of root mean square value) for the muscle deformation (strain) (\%) and deformation rate (\% deformation/s) of dorsal ${ }^{1}$ and ventral $^{2}$ neck muscles between participants who have previously undergone an ACDF and the control group during loaded $120^{\circ}$ arm elevation.

Deformation

\begin{tabular}{lcccccc}
\hline & ACDF & Control & p-value & ACDF & Control & p-value \\
\hline Trapezius & $2.96(1.54)$ & $3.42(2.14)$ & 0.59 & $0.015(0.006)$ & $0.015(0.006)$ & 0.97 \\
SplenCap & $3.51(2.12)$ & $3.38(2.02)$ & 0.89 & $0.022(0.006)$ & $0.021(0.006)$ & 0.66 \\
SemiCap & $3.76(2.73)$ & $3.50(1.98)$ & 0.81 & $0.021(0.005)$ & $0.020(0.007)$ & 0.85 \\
SemiCerv & $3.25(2.11)$ & $3.96(2.79)$ & 0.53 & $0.023(0.008)$ & $0.022(0.005)$ & 0.78 \\
Multifidus & $3.58(1.90)$ & $2.37(0.44)$ & 0.07 & $0.025(0.008)$ & $0.027(0.009)$ & 0.55 \\
SCM & $5.98(3.23)$ & $3.66(2.51)$ & 0.09 & $0.025(0.010)$ & $0.016(0.007)$ & 0.04 \\
LongCap & $8.12(6.52)$ & $2.94(1.18)$ & 0.02 & $0.054(0.035)$ & $0.025(0.009)$ & 0.02 \\
LongCol & $7.49(5.23)$ & $4.05(2.54)$ & 0.08 & $0.062(0.047)$ & $0.031(0.015)$ & 0.07
\end{tabular}

\footnotetext{
${ }^{1}$ Splenius Capitis (SplenCap), Semispinalis Capitis (SemiCap), Semispinalis cervicis (SemiCer).

${ }^{2}$ Sternocleidomastoid (SCM), Longus capitis (LongCap), Longus colli (LongCol).
} 
Table 2) Descriptive statistics (mean (standard deviation) of root mean square value) for the muscle deformation (strain) (\%) of the dorsal and ventral neck muscles of participants who have previously undergone an ACDF and the control group during the first (Rep.1) and final (Rep. 9/10) repetitions of repeated loaded $90^{\circ}$ arm elevation task.

\begin{tabular}{|c|c|c|c|c|c|c|}
\hline & \multicolumn{2}{|c|}{ ACDF } & \multicolumn{2}{|c|}{ Control } & \multirow{2}{*}{$\begin{array}{c}\text { Group Effect } \\
\text { p-value }\end{array}$} & \multirow{2}{*}{$\begin{array}{c}\text { Group x Time } \\
\text { Interaction } \\
\text { p-value }\end{array}$} \\
\hline & Rep. 1 & Rep. 9/10 & Rep. 1 & Rep. 9/10 & & \\
\hline Trapezius & $2.39(1.93)$ & $3.13(2.6)$ & $2.25(1.14)$ & $1.85(1.21)$ & 0.12 & 0.31 \\
\hline SplenCap & $4.5(3.55)$ & $5.16(4.59)$ & $2.72(1.35)$ & $2.8(1.49)$ & 0.08 & 0.38 \\
\hline SemiCap & $3.23(2.87)$ & $4.53(4.71)$ & $3.89(2.49)$ & $3.09(1.37)$ & 0.88 & 0.25 \\
\hline SemiCerv & $3.48(2.92)$ & $3.43(2.21)$ & $2.73(1.53)$ & $2.77(1.71)$ & 0.14 & 0.57 \\
\hline Multifidus & $2.97(1.94)$ & $3.27(1.76)$ & $3.5(3.18)$ & $2.58(1.71)$ & 0.31 & 0.43 \\
\hline SCM & $4.24(2.88)$ & $6.32(6.77)$ & $3.99(3.58)$ & $2.29(1.5)$ & 0.14 & 0.11 \\
\hline LonCap & $4.33(2.79)$ & 5.93(3.56) & $2.03(0.99)$ & $4.13(2.65)$ & 0.005 & 0.87 \\
\hline LonCol & $4.03(4.24)$ & $6.37(4.14)$ & $2.54(1.57)$ & $3.69(2.56)$ & 0.09 & 0.8 \\
\hline
\end{tabular}

${ }^{1}$ Splenius Capitis (SplenCap), Semispinalis Capitis (SemiCap), Semispinalis cervicis (SemiCer).

${ }^{2}$ Sternocleidomastoid (SCM), Longus capitis (LonCap), Longus colli (LonCol). 
Table 3) Descriptive statistics (mean (standard deviation) of root mean square value) for the muscle deformation rate (strain/sec) (\%/s) of the dorsal and ventral neck muscles of participants who have previously undergone an ACDF and the control group during the first (Rep.1) and final (Rep. 9/10) repetitions of repeated loaded $90^{\circ}$ arm elevation task.

\begin{tabular}{|c|c|c|c|c|c|c|}
\hline & \multicolumn{2}{|c|}{ ACDF } & \multicolumn{2}{|c|}{ Control } & \multirow{2}{*}{$\begin{array}{c}\text { Group Effect } \\
\text { p-value }\end{array}$} & \multirow{2}{*}{$\begin{array}{c}\begin{array}{c}\text { Group x Time } \\
\text { Interaction }\end{array} \\
\text { p-value }\end{array}$} \\
\hline & Rep. 1 & Rep. 9/10 & Rep. 1 & Rep. 9/10 & & \\
\hline Trapezius & $0.008(0.004)$ & $0.012(0.009)$ & $0.01(0.005)$ & $0.011(0.005)$ & 0.65 & 0.24 \\
\hline SplenCap & $0.017(0.01)$ & $0.019(0.012)$ & $0.016(0.008)$ & $0.016(0.007)$ & 0.32 & 0.31 \\
\hline SemiCap & $0.018(0.009)$ & $0.02(0.014)$ & $0.016(0.009)$ & $0.016(0.005)$ & 0.42 & 0.72 \\
\hline SemiCerv & $0.018(0.007)$ & $0.023(0.016)$ & $0.016(0.009)$ & $0.019(0.006)$ & 0.23 & 0.8 \\
\hline Multifidus & $0.028(0.017)$ & $0.025(0.018)$ & $0.018(0.014)$ & $0.018(0.006)$ & 0.03 & 0.47 \\
\hline SCM & $0.018(0.008)$ & $0.018(0.009)$ & $0.016(0.01)$ & $0.014(0.008)$ & 0.19 & 0.31 \\
\hline LonCap & $0.028(0.013)$ & $0.028(0.011)$ & $0.018(0.005)$ & $0.02(0.011)$ & 0.01 & 0.54 \\
\hline LonCol & $0.032(0.022)$ & $0.032(0.012)$ & $0.028(0.023)$ & $0.023(0.008)$ & 0.09 & 0.92 \\
\hline
\end{tabular}

${ }^{1}$ Splenius Capitis (SplenCap), Semispinalis Capitis (SemiCap), Semispinalis cervicis (SemiCer).

${ }^{2}$ Sternocleidomastoid (SCM), Longus capitis (LonCap), Longus colli (LonCol). 